\title{
Avaliação da esterilização em autoclaves odontológicas através do monitoramento biológico
}

\author{
Evaluation of dental autoclave sterilization through biological monitoring
}

\section{Fabiana Vieira Vier-Pelisser ${ }^{1}$; Marcus Vinícius Reis Só ${ }^{2}$, Leandro Gremelmaier ${ }^{3}$, Ricardo Bozetti ${ }^{4}$, Audrei Pelisser ${ }^{5}$}

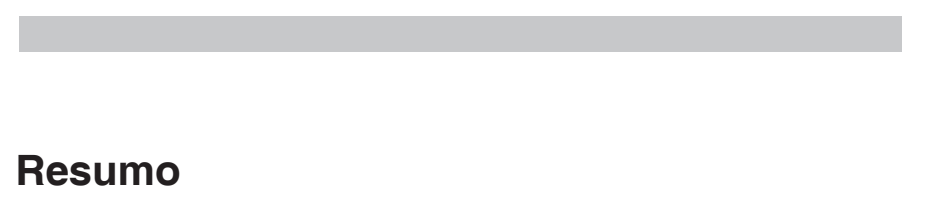

O objetivo deste estudo foi avaliar a ocorrência de esterilização em autoclaves de consultórios odontológicos, mediante o emprego de indicadores biológicos, assim como, através de questionário, conhecer a prática clínica do processamento do instrumental contaminado. Foram introduzidos em 40 autoclaves, juntamente com o instrumental, três indicadores biológicos (próximo ao filtro, no centro e junto à porta). Após, os indicadores (testes e controle) foram incubados por 48 horas, para aferição do meio de cultura. Os indicadores-teste apresentaram mudança da cor do meio de cultura de roxo para amarelo em 14 (35\%) das autoclaves, indicando ausência de esterilização. A maioria dos cirurgiões-dentistas (CDs) associa ao calor úmido, outros métodos de esterilização, como o químico e o calor seco. Nenhum cirurgião-dentista emprega rotineiramente o monitoramento biológico em seu consultório. Dos 31 cirurgiões-dentistas $(77,5 \%)$ que empregam o controle físico e/ou químico da esterilização, apenas $74,2 \%$ dos mesmos, o fazem a cada ciclo. A grande maioria dos cirurgiões-dentistas $(75 \%)$ emprega o envelope para o empacotamento do instrumental. No entanto, $77,5 \%$ dos mesmos não escrevem na embalagem a data da esterilização. Concluiu-se que $35 \%$ das autoclaves analisadas não estão realizando o processo de esterilização do instrumental e que algumas falhas durante o processamento do instrumental contaminado ainda existem e deveriam ser corrigidas.

Palavras-chave: Autoclave, Esterilização, Monitoramento biológico

\section{Abstract}

The aim of this study was to evaluate the occurrence of autoclave sterilization at dental offices by means of biological indicators and questionnaires, as well as to know the clinical practice of processing the contaminated instruments. Three biological indicators (close to the filter, at the center and close to the door) were introduced into 40 autoclaves along with instruments. Next, indicators (test and control) were incubated for 48 hours in order to check the culture medium. The test-indicators had a change in the color of the culture medium from purple to yellow in 14 (35\%) of autoclaves. Most dental surgeons (DS) associate other sterilization methods, such as chemical and dry heat, with damp heat. No Dental Surgeon routinely use biological monitoring at their offices. From the 31 Dental Surgeons $(77.5 \%)$ who use physical and/or chemical control of sterilization, only $74.2 \%$ do it every cycle. The great majority of DS $(75 \%)$ use the envelope for packing instruments. However, $77.5 \%$ of them do not write the sterilization date on the package. It was concluded that $35 \%$ of the analyzed autoclaves did not perform the instrument sterilization process and that some flaws during processing of the contaminated instruments still occur and should be corrected.

Keywords: Mouth neoplasms, Squamous cell carcinoma, Epidemology
${ }^{1}$ Doutora em Estomatologia clínica pela PUCRS e Professora do Curso de Especialização em Endodontia da Uningá (Caxias do Sul - RS)

${ }^{2}$ Doutor em Endodontia pela UNICAMP, Coordenador do Curso de Especialização em Endodontia da Uningá (Caxias do Sul - RS) e Professor de Endodontia da Universidade de Passo Fundo

${ }^{3}$ Aluno do Curso de Especialização em Endodontia da Uningá (Caxias do Sul - RS)

${ }^{4}$ Aluno do Curso de Especialização em Endodontia da Uningá (Caxias do Sul - RS)

${ }^{5}$ Especialista em Implantodontia pela UFSC e Mestre em Cirurgia Bucomaxilofacial pela Ulbra.

Corespondência: Fabiana Vieira Vier-Pelisser

Endereço: Av. Cristóvão Colombo, 1636/306 - Floresta - CEP 90560-001 Porto Alegre - RS

E-mail: endovier@caiweb.com.br

Corespondência: Marcus Vinícius Reis Só Endereço: R. Mostardeiro, 157, cj. 1005 - CEP 90430-001 - Porto Alegre - RS

Corespondência: Leandro Gremelmaier

Endereço: R. Gal. Arcy da Rocha Nóbrega, 401/207. Jardim América CEP 95040-000 - Caxias do Sul - RS

Corespondência: Ricardo Bozetti

Endereço: R. Bento Gonçalves, 23. Centro - CEP 95945-000 - Pouso Novo - RS

Corespondência: Audrei Pelisser

Endereço: R. Cel. Manoel Py, 225/302. São João - CEP 90550-000

Porto Alegre - RS

\section{Introdução}

O controle de infecção em Odontologia tem sido bastante discutido, em virtude da elevada possibilidade de contaminação durante o atendimento clínico-cirúrgico, permitindo a ocorrência de infecções cruzadas e a proliferação de doenças (ESTRELA; ESTRELA, 2003).

Uma das medidas imprescindíveis para o controle de infecção em Odontologia é a realização da esterilização dos instrumentais odontológicos.

Exclusivamente o monitoramento biológico é capaz de assegurar a efetividade da esterilização, devendo ser feito semanalmente, sendo seu resultado registrado e mantido em arquivos de controle (GUANDALINI et al., 1997). Da mesma forma, todos os procedimentos que envolvem o processamento do instrumental contaminado devem ser rigorosamente e regularmente analisados, para que se tenha certeza do êxito deste processo.

Assim, parece relevante a existência de estudos que objetivem a comprovação do processo de esterilização em autoclaves odontológicas, mediante o emprego do monitoramento biológico.

\section{Revisão da literatura}

Durante o atendimento direto ao paciente ou mesmo nas atividades de apoio, como no preparo do ambiente de trabalho e no processamento do instrumental contaminado, a equipe da saúde entra em contato com material biológico (sangue, saliva, escarro etc.), que pode estar alojando micro-organismos. Dessa forma, os materiais, os instrumentais, os equipamentos e o próprio ambiente clínico de trabalho devem ser considerados, após o atendimento, como potencialmente contaminados por micro-organismos transmissíveis de doenças (OPPERMANN; PIRES, 2003). 
O Ministério da Saúde (BRASIL, 1994) recomendou a classificação de Spauling para objetos inanimados, conforme o risco potencial de transmissão de infecção, em artigos críticos, semicríticos e não críticos. Assim, os primeiros (que entram em contato com o tecido subepitelial) devem ser esterilizados. Os segundos, ou seja, que tocam mucosa íntegra, entrando em contato com saliva, devem, idealmente, sofrer processo de esterilização ou, no mínimo, serem desinfectados quando não puderem ser esterilizados por processos físicos. Já os últimos, que entram em contato com a pele íntegra ou que não entram em contato com o paciente, apenas um processo de desinfecção é aceitável (GRAZIANO; SILVA; BIANCHI et al., 2000; GUIMARÃES JUNIOR, 2001).

Esterilização é o processo de destruição de todos os microorganismos, inclusive os esporulados, mediante aplicação de agentes físicos e químicos (glutaraldeído a $2 \%$ ) ou ambos (HUYS, 2004).

A esterilização, empregando agentes físicos, pode ser realizada em estufa (calor seco) ou em autoclave (calor úmido). Com a utilização da autoclave, o tempo de esterilização é inferior aos outros métodos, sendo este fator preponderante quando da escolha pelos cirurgiões-dentistas. A esterilização faz-se pela ação do vapor de água superaquecido e mantido sob pressão, ocorrendo à temperatura de $121^{\circ} \mathrm{C}$ por período de 15 a 30 minutos (JORGE, 2002). Os aparelhos são práticos, de fácil operacionalização e apresentam-se em diferentes tamanhos, capacidade e desenhos (GUANDALINI; MELO; SANTOS, 1997). Este processo admite a esterilização de artigos em embalagens permeáveis ao vapor não devendo utilizar-se de recipientes metálicos fechados ou sem perfurações para penetração de vapor (DONATELLI, 2005).

No entanto, o processamento do instrumental contaminado compreende uma série de medidas: descontaminação dos mesmos mediante sua imersão em detergentes enzimáticos, limpeza, enxágue, secagem, empacotamento, esterilização e armazenamento. Assim, o preparo do instrumental contaminado para a reutilização em procedimentos clínicos é considerado como fator fundamental para o controle de infecção cruzada. A falha em um desses procedimentos pode afetar o processo de esterilização, comprometendo a manutenção da cadeia asséptica durante o atendimento odontológico (GUANDALINI; MELO; SANTOS, 1999).

Todos os equipamentos produtores de calor seco ou úmido utilizados na esterilização de artigos odontológicos devem ser mantidos em condições adequadas de funcionamento, submetidos à aferição e manutenção preventiva anual, com registro ou certificação técnica autorizada por órgão competente local (CONSELHO REGIONAL DE ODONTOLOGIA DO RIO GRANDE DO SUL, 2002).

É importante que o método de esterilização seja realmente efetivo e que o mesmo seja monitorado periodicamente. Isto pode ser feito por meio de três indicadores: físico, químico e biológico (ESTRELA, 2004).

O monitoramento físico consiste na leitura dos dispositivos presentes no aparelho, como o termômetro e monovacuômetro na autoclave e o termostato e termômetro acessório na estufa, comparando-a com o padrão que vem especificado no manual de instruções do equipamento. Este monitoramento apenas aponta para os diferenciais de pressão e temperatura, no caso da autoclave, não garantindo a efetividade do processo de esterilização, devendo ser aferido em todos os ciclos. Na monitoração física, verifica-se também se os tempos de aquecimento e esterilização são iguais aos recomendados pela Secretaria da Saúde (DONATELLI, 2005).

Os indicadores químicos, na forma de tiras de celulose ou fita adesiva, são utilizados apenas para diferenciar os pacotes que passaram pelo processo de esterilização daqueles que ainda não passaram (OPPERMANN; PIRES, 2003). O sistema de reagentes químicos impregnados nas fitas são sensíveis a determinadas temperaturas, mudando de cor quando passam pelo processo de esterilização (JORGE, 2002). Seu emprego deve ser considerado como um adjunto a um programa de monitoramento biológico, uma vez que as fitas adesivas apenas asseguram os parâmetros de temperatura e presença de vapor.
O monitoramento biológico está representado por tiras de celulose, meios de cultura ou outros veículos e uma suspensão de esporos bacterianos. Em autoclaves, utiliza-se o Bacillus stearothermophilus e, em estufas, o Bacillus subtilis (GUANDALINI; MELO; SANTOS, 1999; JORGE, 2002).

Existem três gerações de indicadores biológicos, de acordo com a ordem crescente de velocidade e rapidez na obtenção dos resultados (SCALLI, 1997). Os de primeira geração ou convencionais consistem em tiras de papel contendo esporos dessecados que, após serem expostos ao ciclo de esterilização, são incubados e inoculados através do Método da Turbidimetria. Após dois e sete dias, é feita a análise, para verificar-se a presença ou não de crescimento bacteriano.

Os indicadores biológicos de segunda geração, ou autocontidos, com tempo de resposta de no máximo 48 horas, são compostos por uma tira de papel contendo esporos dessecados. Esta tira é armazenada em uma ampola plástica que também acondiciona uma ampola de vidro contendo um caldo nutriente próprio para o cultivo de micro-organismos.

Os indicadores biológicos de terceira geração, também autocontidos, possuem tempo de resposta de no máximo três horas, por método de fluorescência. Ao meio de cultura, é acrescido um substrato que fornece um produto fluorescente facilmente detectável quando nele se incide uma luz ultravioleta.

Os indicadores biológicos são utilizados para testar a eficácia do processo quanto à destruição dos micro-organismos, devendo ser colocados em locais estratégicos da autoclave, conforme seu tamanho, sendo indispensável a colocação próximo ao filtro, no centro da autoclave e próximo à porta, pois são considerados pontos críticos para a ação do agente esterilizante (OPPERMANN; PIRES, 2003).

O Ministério da Saúde (BRASIL, 2000) recomenda o uso dos indicadores biológicos semanalmente, assim como durante a instalação e manutenção da autoclave, e também em todas as cargas que contenham artigos implantáveis. Os resultados do monitoramento biológico devem ser documentados e arquivados.

O objetivo do presente estudo foi avaliar a ocorrência de esterilização em autoclaves de consultórios odontológicos, mediante o emprego de indicadores biológicos de segunda geração, assim como conhecer a prática clínica do processo de esterilização realizado por cirurgiões-dentistas que usam a autoclave.

\section{Material e Métodos}

O processo de esterilização de 40 autoclaves odontológicas foi monitorado neste estudo, mediante o emprego de 160 indicadores biológicos (4 para cada ciclo de esterilização).

Para tanto, foram realizadas visitas a consultórios odontológicos da região de Caxias de Sul, onde os Cirurgiões-Dentistas foram convidados a participar da pesquisa.

Os participantes da pesquisa assinaram um Termo de Consentimento Informado, permitindo a realização do experimento em seu consultório, assim como preencheram um questionário fechado, com perguntas pessoais e relativas ao processamento do instrumental contaminado em seu consultório.

Para a realização do experimento, foi solicitada aos Cirurgiões-Dentistas que não fosse alterada a rotina normal do processo de esterilização, às expensas da realização da visita.

Foram introduzidos na autoclave, juntamente com o instrumental a ser esterilizado, três indicadores biológicos ou ampolas (Clean-Test, Campo Mourão, Brasil), sendo dispostos da seguinte forma: um próximo ao filtro $(A)$, outro no centro $(B)$ e o último junto à porta $(\mathrm{C})$.

Estas ampolas, previamente à esterilização, foram acondicionadas em envelopes compostos por papel grau cirúrgico, filme laminado de poliéster com polipropileno (Vedamax, Zermatt Ind. e Com. Ltda, Itatiba, São Paulo) devidamente selados.

Uma quarta ampola (D) não foi submetida ao processo de esterilização, sendo utilizada como indicador-controle. 
Após 15 minutos do término do ciclo de esterilização, os indicadores biológicos foram retirados da autoclave, sendo a ampola de vidro interna, contendo o meio de cultura, quebrada, para que ocorresse a mistura entre o meio e a tira impregnada com os esporos. O mesmo procedimento foi efetuado no indicador-controle.

Sequencialmente, os três indicadores-teste $(A, B$ e $C)$ e o indicador-controle foram inseridos na Mini-incubadora (Cristófoli, Campo Mourão, Brasil), permanecendo neste local por $48 \mathrm{~h}$.

A aferição da ocorrência de alteração da cor do meio de cultura (de roxo para amarelo) foi realizada em 24 e 48h, comprovando a não ocorrência da esterilização. A ocorrência de esterilização foi considerada quando o meio de cultura, nestes mesmos tempos experimentais, nas ampolas-teste, não sofreu alteração de cor, ou seja, permaneceu roxo (Figura 1).

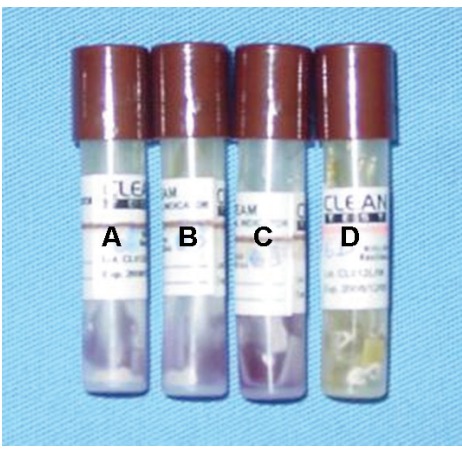

Figura 1. Indicadores biológicos A, B, C e D, após 48 h de incubação, mostrando manutenção da cor roxa nas ampolas-teste (A, B e C), indicando ocorrência da esterilização, e alteração da cor do meio de cultura de roxo para amarelo na ampola-controle (D), demonstrando ausência de esterilização.

Os dados relativos aos 160 indicadores-teste empregados foram coletados e distribuídos em tabelas para posterior análise estatística dos resultados, mediante o emprego do Teste de Comparação de Duas Proporções («2), em um nível de significância de 5\%.

O questionário contemplava perguntas relativas aos seguintes tópicos: marca e modelo de sua autoclave e há quanto tempo ele estava utilizando-a; se o cirurgião-dentista empregava alguma outra forma de esterilização além da autoclave; quem realizava a limpeza e a esterilização dos instrumentais no seu consultório; se o cirurgião-dentista usava algum tipo de artifício para monitoramento da esterilização e qual; de quanto em quanto tempo realizava este monitoramento; qual tipo de embalagem que o mesmo utiliza para o empacotamento do instrumental; se o mesmo escrevia na embalagem a data em que realizou a esterilização; se o cirurgiãodentista fazia o processo de reesterilização do instrumental quando o mesmo não era utilizado e ficava somente armazenado e, se sim, de quanto em quanto tempo; de que forma o cirurgião-dentista realizava o vedamento da embalagem; qual tipo de água utilizada na autoclave e, finalmente, após o término do ciclo de esterilização, como era efetuado o processo de secagem do instrumental.

\section{Resultados}

Das quarenta autoclaves avaliadas neste estudo, 14 (35\%) não esterilizaram, já que os indicadores-teste apresentaram mudança da cor do meio de cultura de roxo para amarelo, sendo este resultado estatisticamente significativo $(P=0,014)$. Em todas as análises, os resultados dos indicadores-teste foram semeIhantes, ou seja, a esterilização ocorreu ou não. As ampolas (A, B e C), independentemente da posição das mesmas no interior da autoclave, mantiveram-se roxas ou amarelas, respectivamente. Já os indicadores-controle de todas as avaliações apresentaram turvação do meio (cor amarela).
As marcas das autoclaves monitoradas biologicamente neste estudo e os resultados quanto à efetividade ou não da esterilização estão apresentadas na Tabela 1.

O tempo de uso das autoclaves analisadas foi de até 3 anos em 19 (47,5\%) casos, de 4 a 9 anos em 16 (40\%) casos e acima de 10 anos $4(10 \%)$ casos. Um participante não soube relatar o tempo de uso do equipamento.

Tabela 1. Marcas das autoclaves monitoradas biologicamente e os resultados quanto à efetividade ou não da esterilização

\begin{tabular}{lcccc} 
& & & \multicolumn{2}{c}{ Esterilização } \\
\cline { 4 - 5 } Marca & $\mathrm{n}$ & $\mathrm{f}(\%)$ & Positivo & Negativo \\
\hline Cristófoli & 25 & 62,5 & 18 & 7 \\
Dabi Atlante & 5 & 12,5 & 3 & 2 \\
Fabbe & 1 & 2,5 & 1 & - \\
Kavo & 1 & 2,5 & 1 & - \\
Odontobrás & 3 & 7,5 & 2 & 1 \\
Sercon & 3 & 7,5 & 1 & 2 \\
Stermax & 2 & 5,0 & - & 14
\end{tabular}

Dezenove $(47,5 \%)$ cirurgiões-dentistas empregam a autoclave como único método de esterilização em seu consultório. Além do calor úmido, $11(27,5 \%)$ profissionais utilizam meios químicos. Já $9(22,5 \%)$ empregam o calor seco e $1(2,5 \%)$ associa os três métodos.

A limpeza do instrumental contaminado é realizada pela secretária, pelo cirurgião-dentista e pela atendente de consultório dentário em 25 (62,5\%), 10 (25\%) e 5 (12,5\%) dos casos, respectivamente.

A maioria, 31 (77,5\%) dos cirurgiões-dentistas realizam algum tipo de monitoramento da esterilização, sendo este físico em 4 (10,0\%), químico em 17 (42,5\%) e ambos em 10 (25,0\%), enquanto que $09(22,5 \%)$ dos profissionais não efetuam nenhum tipo de controle do processo de esterilização.

O monitoramento da esterilização é realizado a cada ciclo, semanalmente e quinzenalmente em $23(74,2 \%), 6(19,4 \%), 1$ $(3,2 \%)$, respectivamente. Um cirurgião-dentista $(3,2 \%)$ não respondeu esta pergunta.

Referente ao empacotamento do instrumental, a grande maioria dos cirurgiões-dentistas (75\%) optou pelo emprego dos envelopes. Outros tipos de embalagens mencionadas foram papel Kraft, papel grau cirúrgico e TNT.

Ao efetuar a esterilização, 31 (77,5\%) profissionais não escrevem na embalagem a data da realização da mesma.

A reesterilização do instrumental, quando o mesmo ficou somente armazenado, é realizada por $18(45 \%)$ cirurgiões-dentistas. O tempo em que os mesmos executam este processo está descriminado na Tabela 2.

Tabela 2. Tempo em que os cirurgiões-dentistas reesterilizam o instrumental quando o mesmo ficou somente armazenado.

\begin{tabular}{cc}
\hline Dias & $\mathrm{N}$ \\
\hline 5 & 1 \\
7 & 2 \\
15 & 2 \\
20 & 2 \\
30 & 3 \\
60 & 1 \\
90 & 1 \\
180 & 2 \\
Quando desejo reutilizar & 1 \\
Não especificou & 3 \\
\hline Total & 18 \\
\hline
\end{tabular}


O vedamento da embalagem foi realizado através de seladora, fita adesiva ou ambos em $12(30 \%), 19(47,5 \%)$ e $9(22,5 \%)$, respectivamente.

A água empregada na autoclave no processo de esterilização foi destilada, potável ou deionizada em 36 (90\%), 2 (5\%) e 1 $(2,5 \%)$, respectivamente. Um cirurgião-dentista $(2,5 \%)$ utiliza tanto a água destilada quanto a deionizada.

Após o término do ciclo de esterilização, o processo de secagem é efetuado mantendo a porta fechada em 2 (5\%) dos casos, deixando a porta entreaberta por alguns minutos em 38 $(95 \%)$ dos casos. Nenhum cirurgião-dentista relatou retirar o instrumental da autoclave antes do término do ciclo de secagem.

Após o término do ciclo de esterilização, o processo de secagem é efetuado, mantendo a porta fechada em 2 (5\%) dos casos, deixando a porta entreaberta por alguns minutos em 38 $(95 \%)$ dos casos. Nenhum cirurgião-dentista relatou retirar o instrumental da autoclave antes do término do ciclo de secagem.

\section{Discussão}

O processo de esterilização do instrumental em consultório odontológico é um dos requisitos fundamentais para um efetivo controle de infecção. Apesar de o calor úmido ser o método de esteri lização mais indicado, apresenta falhas quando a autoclave não for utilizada corretamente ou quando apresentar algum problema técnico. Estas falhas somente poderão ser detectadas realmente através do monitoramento da esterilização (MOLINARI; GLEASON; MERCHANT, 1994).

Apesar da existência de três tipos de monitoramento da esterilização (físico, químico e biológico), exclusivamente este último, garante a efetividade do processo (STELLA, 1995; GUANDALINI; MELO; SANTOS,1997, CARDOSO, 2005).

Os resultados do presente estudo são surpreendentes e preocupantes, visto que $35 \%$ das autoclaves testadas, através do monitoramento biológico, não estavam realizando o processo de esterilização do instrumental. Estes dados são alarmantes, tendo em vi sta o fato de que o termo esterilização não pode ser empregado com sentido relativo. Um objeto ou substância estão ou não esterilizados; jamais poderão estar meio ou quase esterilizados (JORGE, 2002). O monitoramento biológico emprega como micro-organismoteste uma suspensão de esporos bacterianos (Bacillus stearothermophilus) (JORGE, 2002), por serem as formas bacterianas esporuladas mais resistentes ao processo de esterilização do que as vegetativas (ESTRELA, 2004)

Os resultados desta pesquisa são corroborados pelo estudo de Field, Field e Martin (1988), que analisaram estufas e autoclaves em consultórios odontológicos americanos, demonstrando que 12 a 33\% dos equipamentos apresentaram falhas no processo de esterilização.

Na presente investigação, a maioria dos cirurgões-dentistas $(77,5 \%)$ relatou fazer uso de algum tipo de monitoramento, a cada ciclo, em suas autoclaves. No entanto, todos os pesquisados não relataram o emprego do monitoramento biológico. Dessa maneira, não sabem efetivamente se a autoclave está ou não esterilizando o instrumental. Este tipo de controle é fundamental e indispensável no consultório odontológico. Maior fiscalização por parte da Secretaria Municipal de Saúde de cada município deveria ser realizada, de modo que fosse cumprido o que preconiza, ou seja, que este monitoramento fosse realizado semanalmente, sendo seu resultado registrado e mantido em arquivos de controle (GUANDALINI; MELO; SANTOS, 1997)

O monitoramento biológico deve ser realizado com relativa frequência, visto que, deste modo, a detecção de falhas dá-se mais rapidamente, permitindo um atendimento odontológico dentro de padrões de biossegurança, diminuindo o risco de infecções, aumentando a segurança do paciente, a credibilidade do profissional e o custo de manutenção do equipamento (CARDOSO, 2005).
Os resultados deste experimento apontaram para o fato de que, independentemente da posição no interior da autoclave em que o instrumental é colocado (próximo ao dreno, à porta ou no centro), o processo de esterilização ocorre, visto que todos os indicadores-teste apresentaram os mesmos resultados, em uma mesma aferição. Isso faz com que, buscando uma minimização dos custos deste monitoramento, talvez possa-se empregar exclusivamente um indicador teste e um indicador controle, para cada avaliação. Além disso, não há a necessidade do profissional adquirir uma mini-incubadora para a realização deste monitoramento. As ampolas podem ser levadas a locais que possuam estufas bacteriológicas calibradas em $56^{\circ} \mathrm{C}$, sendo analisadas, então, em 24 e 48h, para verificação de turvação ou não do meio. Neste sentido, o fator custo não poderia ser levado em consideração para a não realização desta importante medida de controle de infecção.

Um fato que merece menção é que $22,5 \%$ dos profissionais não realizam nenhum tipo de monitoramento do processo de esterilização. $O$ tipo de monitoramento mais utilizado pelos cirurgiõesdentistas que participaram deste estudo é o químico $(54,9 \%)$, seguido pela combinação de monitoramento físico-químico $(32,2 \%)$ e do físico exclusivamente (12,9\%). Apesar de o monitoramento biológico ser o único que verifica a efetividade do processo, o químico e o físico fazem-se necessários, devendo ser empregados coadjuvantemente ao monitoramento biológico, objetivando a identificação de possíveis falhas no processo de esterilização que possam ocorrer em cada ciclo, de maneira particular. Apesar dos resultados demonstrarem que a maioria $(74,2 \%)$ dos cirurgiões-dentistas realiza 0 monitoramento físico e/ou químico a cada ciclo, alguns profissionais o fazem semanalmente ou quinzenalmente.

No presente estudo, várias marcas comerciais de auto- claves foram analisadas quanto à efetividade da esterilização. Com base na Tabela 1, percebe-se que, apesar dos diferentes resultados obtidos, não se pode, em função do número amostral pequeno, definir se uma ou outra é mais efetiva. É imperioso salientar que, independentemente da marca do equipamento, deve-se realizar a manutenção periódica do mesmo, conforme as especificações de cada fabricante. A ANVISA (2006) adverte que a limpeza das tubulações internas deve ser realizada por técnico especializado e que a troca de água seja efetuada de acordo com o que preconiza o fabricante do equipamento.

A falta de manutenção técnica das autoclaves analisadas neste estudo pode ter contribuído para o alto índice de ausência de esterilização. Apesar do questionário não contemplar esta pergunta, pode-se fazer a ilação de que autoclaves com mais tempo de uso tenham uma maior probabilidade de possuir um problema técnico, desde que o profissional não tenha realizado nenhum tipo de manutenção no equipamento.

Apesar de o calor úmido ser a forma de esterilização mais rápida e eficiente (ESTRELA; ESTRELA, 2003), o emprego de outros métodos não está contraindicado, desde que sejam controladas as variáveis que possam influenciar no processo de esterilização. Os resultados desta investigação apontam para o fato de que a maioria dos profissionais $(52,5 \%)$ associa diferentes métodos de esterilização em seu consultório.

Para que o profissional da área da saúde trabalhe inteirado numa prática de controle de infecção, é importante a compreensão de que o processamento do instrumental contaminado não compreende exclusivamente a esterilização propriamente dita, e sim, um conjunto de medidas em sequência que vai desde a descontaminação até o armazenamento (GUANDALINI; MELO; SANTOS, 1999). Desta forma, cada uma das etapas deve ser rigorosamente realizada dentro de padrões que garantam a efetividade do processo de esterilização.

Assim, a limpeza do instrumental contaminado merece destaque. No presente estudo, percebeu-se que em $62,5 \%$ dos consultórios analisados, esta limpeza é realizada pela secretária, auxiliar esta que realizou curso prévio de treinamento em um órgão competente para tal, como é o caso da atendente de consultório dentário. Desta forma, o profissional deve instruí-la quanto à melhor maneira de realizar essa tarefa, assim como monitorar sua execução. 
Os envelopes pré-fabricados são empregados por $75 \%$ dos cirurgiões-dentistas, para o empacotamento do instrumental. Estes dispositivos, além de permitirem a passagem do calor e de serem fornecidos em diferentes tamanhos, são extremamente práticos, permitindo o emprego tanto de fitas adesivas quanto de seladora, para o vedamento da embalagem. Além disso, permitem a visualização do instrumental contido no seu interior. Jorge (2002) ressaltou que também podem ser empregados, para o empacotamento do instrumental, o papel manilha ou kraft, tecido de algodão cru ou filme de poliamida (50 a $100 \mu \mathrm{m}$ de espessura), não podendo ser utilizados o papel alumínio e as caixas metálicas fechadas, pois não permitem a passagem do vapor.

$O$ instrumental esterilizado deve ser armazenado em local exclusivo, separado dos demais em armários fechados, protegido de poeira, umidade e insetos, a uma distância mínima de $20 \mathrm{~cm}$ do teto e $5 \mathrm{~cm}$ da parede, respeitando-se o prazo de validade da esterilização (SANTOS, 2006).

A data do processo de esterilização não é escrita nas embalagens pela maioria $(77,5 \%)$ dos profissionais. Isso demonstra um descaso dos cirurgiões-dentistas quanto ao prazo de validade do processo, visto que existem inúmeros instrumentais que não são empregados rotineiramente na clínica, mas que devem estar disponíveis e prontos para o uso em caso de necessidade. Estes instrumentais poderiam estar sendo empregados com o prazo de validade vencido, ou seja, não tendo mais a garantia do processo de esterilização. O curioso, no entanto, é que quando os cirurgiõesdentistas foram questionados se fazem ou não o processo de reesterelização do instrumental, apenas $45 \%$ dos mesmos relataram que o faz no mais variado intervalo de tempo (Tabela 2). Neste momento, porém, cabe a pergunta: Como os profissionais sabem relatar o intervalo de tempo que aguardam para reesterilizar o instrumental embalado e armazenado, mas não utilizado, se não escrevem a data da esterilização nas embalagens? Ou seja: Como sabem o momento de esterilizar novamente o instrumental sem uso?

A resolução SS-374, de 15 de dezembro de 1995, recomenda 0 prazo de 7 dias de validade para os artigos esterilizados por processo físico (SÃO PAULO, 1995). No entanto, dos $18(45 \%)$ cirurgiões-dentistas que reesterilizam seu instrumental quando o mesmo ficou armazenado, apenas 3 o fazem dentro deste limite de tempo.

É concebível, no entanto, que os artigos esterilizados fiquem armazenados por algum tempo antes de serem utilizados. Daí a importância dos mesmos serem acondicionados em embalagens que previnam a recontaminação (HUYS, 2004) e que as mesmas sejam bem vedadas. $O$ presente estudo demonstrou que fitas adesivas e seladoras são empregadas pelos cirurgiões-dentistas para este fim, sendo ambos os métodos aceitáveis para o selamento da embalagem.

Como a autoclave emprega o calor úmido, cuidado deve ser dispensado no momento de se remover o instrumental do aparelho, pois a presença de umidade no pacote pode danificar o mesmo, propiciando a sua contaminação. Atualmente existem autoclaves que apresentam dispositivos de secagem do instrumental através de sucção de ar, aproveitando o calor dos instrumentos que foram aquecidos pelo vapor (JORGE, 2002). Todos profissionais questionados nesta pesquisa relataram que realizam o processo de secagem como manda o fabricante, ou seja, deixam a porta entreaberta por alguns minutos, antes de remover o instrumental do interior do aparelho.

As informações originadas nesta pesquisa apontam à necessidade da realização periódica do monitoramento biológico nas autoclaves de consultórios odontológicos, para um controle efetivo do processo de esterilização, objetivando um atendimento clínicocirúrgico dentro de padrões de biossegurança. Da mesma forma, as respostas obtidas no questionário realizado, quanto à conduta dos cirurgiões-dentistas durante o processamento do instrumental contaminado conduzem a uma reflexão sobre a responsabilidade do cirurgiões-dentistas no controle de infecção, almejando uma mudança de conduta, de forma a garantir um atendimento clínico-cirúrgico de qualidade ao paciente.

\section{Conclusão}

Com base na metodologia empregada e nos resultados obtidos, é lícito concluir que:

- $35 \%$ das autoclaves analisadas neste estudo não estão realizando o processo de esterilização do instrumental;

- nenhum cirurgião-dentista emprega rotineiramente o monitoramento biológico em seu consultório;

- a maioria $(52,5 \%)$ dos cirurgiões-dentistas associa ao calor úmido, outros métodos de esterilização, como o químico e o calor seco;

- dos 31 cirurgiões-dentistas (77,5\%) que empregam o controle físico e/ou químico da esterilização, apenas $74,2 \%$ dos mesmos, o fazem a cada ciclo;

- a grande maioria dos cirurgiões-dentistas (75\%) emprega o envelope para o empacotamento do instrumental;

- $\quad 77,5 \%$ dos cirurgiões-dentistas não escrevem na embalagem a data da esterilização;

- dos 18 (45\%) cirurgiões-dentistas que reesterilizam seu instrumental quando o mesmo ficou armazenado, apenas 3 $(7,5 \%)$ o fazem dentro de uma semana.

\section{Referências}

ANVISA. Serviços Odontológicos: Prevenção e Controle de Riscos. 2.ed. Brasília. p. 156, 2006.

BRASIL. Ministério da Saúde. Coordenação de Controle de Infecção Hospitalar. Procedimentos de Artigos e Superfícies em Estabelecimentos de Saúde. 2.ed. Brasília. p. 50, 1994.

BRASIL. Ministério da Saúde. Controle de Infecções e a Prática Odontológica em Tempos de AIDS - Manual de Condutas. Brasília, p. 50,2000 .

CARDOSO, D. R. Rotina de Monitoração Física, Química e Biológica para Estufas e Autoclave em Consultório Odontológico. 2005. $102 f$. Dissertação (Mestrado) - Curso de Pós-Graduação em Engenharia Elétrica e Informática Industrial, Centro Federal de Educação Tecnológica do Paraná, Curitiba, 2005.

CONSELHO REGIONAL DE ODONTOLOGIA DO RIO GRANDE DO SUL. Norma Técnica de Biossegurança em Estabelecimentos Odontológicos e Laboratórios de Prótese do Rio Grande do Sul. Porto Alegre, 2002.

DONATELLI, L. J. P. Manual de Biossegurança para Odontologia. Campo Mourão: Cristófoli Biossegurança. 105p, 2005.

ESTRELA, C.; ESTRELA, C. R. A. Controle de Infecção em Odontologia. São Paulo: Artes Médicas. p. 188, 2003.

ESTRELA, C. Ciência Endodôntica. São Paulo: Artes Médicas. p. $455,2004$.

FIELD, E. A.; FIELD, J. K.; MARTIN, M. S. Time, Steam, Temperature (TST) Control Indicators to Measure Essential Sterilization Criteria for Autoclaves in General Dental Practice and the Community Dental Service. Br. Dent. J. London. v. 164. no. 6, p. 183-186, Mar. 1988.

GRAZIANO, K. U.; SILVA, A.; BIANCHI, E. R. F. Limpeza, Desinfecção, Esterilização de Artigos e Antissepsia. In: FERNANDES, et al. Infecção Hospitalar e suas Interfaces na Área da Saúde. São Paulo: Atheneu, p. 266-315, 2000. 
GUANDALINI, S. L.; MELO, N. S. F. O.; SANTOS, E. C. P. Biossegurança em Odontologia. 2. ed. Curitiba: Odontotex. p. 161, 1999.

GUANDALINI, S. L.; MELO, N. S. F. O.; SANTOS, E. C. P. Como Controlar a Infecção na Odontologia. Ribeirão Preto: GNATUS. p.88, 1997.

GUIMARÃES JUNIOR, J. Biossegurança e Controle de Infecção Cruzada em Consultórios Odontológicos. São Paulo: Santos. p.536, 2001.

HUYS, J. Sterilization of Medical Supplies by Steam. Heart Consultancy. Wageningen. The Netherlands: HEART Consultancy. p. 295, 2004.

JORGE, A. O. C. Princípios de Biossegurança em Odontologia. Rev. Biociênc. Taubaté. v.8. n.1, p. 7-17, jan./jun. 2002.

MOLINARI, J. A.; GLEASON, M. J.; MERCHANT, V. A. Sixteen Years of Experience with Sterilization Monitoring. Compend. Contin. Educ. Dent., Newtown. v. 15. n. 12, p. 1422-1432, Dec. 1994.

OPPERMANN, C. M.; PIRES, L. C. Manual de Biossegurança para Serviços de Saúde. Porto Alegre: PMPA/SMS/CGVS. p. 80, 2003.

SANTOS, A. M. S. Serviços Odontológicos: prevenção e controle de riscos. Brasília: ANVISA. p. 152, 2006.

SÃO PAULO (Estado). Secretaria de Saúde. Resolução SS-392, de 29 de junho de 1994. Aprova norma técnica sobre a Organização de Centro de Material e Noções de Esterilização. Diário Oficial do Estado. São Paulo. Seção 1.

SCALLI, P. N. Teste de Bowie e Dick: "bom, barato e muito útil". Rev. SOBECC. São Paulo. v. 2. n. 1, p. 13-14, jan./mar. 1997.

STELLA, S. R. B. R. Produção e Controle de Indicadores Biológicos para Esterilização à Vapor. Rev. Bras. Anal. Clin. Rio de Janeiro. v. 27. n. 1, p. 31-6, 1995. 